\title{
Explaining Connotation of Regional Green Transition
}

\author{
Chongmei WANG \\ ${ }^{1}$ School of administration, Shandong Institute of Business and Technology, Yantai, China \\ ${ }^{2}$ Shandong collaborative innovation center of energy economy, Shandong, China
}

\begin{abstract}
The paper studied the connotation and scope on the regional green transformation combination with system theory on the base many literatures. Different learners have already different view from all kinds of fields. It gave finally the green transition definition from synergy and system innovation. It pointed green transition system is open, interaction. The system has the character of synergy and evolution.
\end{abstract}

KEYWORD: green transition; system science; synergy

\section{LITERATURE REVIEW}

With searching for Chinese journal, doctor's and Master's thesis, important conference papers and important newspaper full-text database from 1979 to 2011 by the keywords "green transformation, green transition", it shows that there are seldom professional papers and literature writings about green transition. In our country, the related literatures are very a rare too. There are 208 relevant journal articles, 389 from the Chinese newspaper full text database, 13 from Chinese important conference papers full-text database. It includes 64 core papers. In the journal literatures, there are 27 news reports and summaries of the work of government departments, which shows the green transformation of the theoretical reference value is limited. And most of the academic achievements are in the green transformation of Shanxi Province, Liaoning Province as the research background. According to local realities, they put forward certain suggestions from the green transformation in practice. At the moment, there are few researches about how to build the theoretical framework of regional green transformation and how to assess the regional green transformation ability. Although this figure does not really show that the development of green transformation theory and practice in China and international community, but it can reflects the degree of concern from academics.

Government officials and entrepreneurs concerned about the green transformation. And it can also reflect social interests and acceptable levels when the green transformation only as a noun.

According to the existing literatures, foreign countries already have "green transformation" formulation, but there are little green transformation literatures from the field of economy. John Rensenbrink (1999) has the representative work "Against all odds: the green transformation of American politics" and Peter Wallshall (2002) have the "green transformation of the spirit" [1-2]. Kevin Knobloch (2009) and so on proposal "Transition to green" [3]. Now many areas and industries in our country are proceeding to green transformation, but "green transformation" mostly be seen as a widely accepted goal orientation. It lacks systematic theoretical research and Practical measures.

Huang Lucheng (2000) thought that Regional innovation system is a System and policy network. It includes all kinds of Main elements and Nonprincipal elements. And it can coordinate the relationship between the various elements in Specific economic area. On the basis of accounting in China's economic and resource consumption[4]. $\mathrm{Hu}$ Angang (2005) considered that China should replace Black economic growth model with green development [5]. Rong-Bing Huang (2006) proposed a simple qualitative description about innovation integrated system of Mining city which contains cultural innovation, institutional innovation, technological innovation, management innovation and regional innovation [6]. Yu Hai (2011) proposed that need starting from the root of problems and systemic innovation, systems thinking basic strategies and approaches to promote and achieve green growth on the China in the "Twelfth FiveYear" period [7]. Zhu dajian (2011) put forward that purely technical innovation can not promote urban development going to the road of sustainability. He emphasizes the urban green transformation need from technology innovation to system innovation 
[8]. Chinese Academy of Social Sciences Institute of Industrial Economics research group (2011) asked that the green transformation of the Chinese industry needs to speed up the mechanism innovation [9]. Li Xiaoxi (2011) pointed out that the green economy plus a "green" in the front of economy, but it is adding new constraints to consumers, businesses and government decision-making [10].

It can be seen from the green transformation theory and the status analysis. Now it lacks green transformation research from system innovation. So it can not form transition practice theoretical support and policy guidance. In response to this defect, this article selects system innovation as an internal organizational system and the external environment as an external organization system. A necessary prerequisite to the study that research the conspiracy relation between Heter-organization and subject system is distinguishing the conspiracy relation between internal organizational system and external organization system.

\section{THE CONNOTATION OF GREEN TRANSITION}

According to the literature retrieval, we found not many studies on the Green transition of academic circle, focusing its research after 2008, so far not yet unified concept of green transition. On May 16, 2008, Taiyuan City, Shanxi province has developed the first national "green transformation" standard system, introduced to promote "green transition regulations (draft)" defined on the Green transition. "Transformation" comes from the field of chemistry the term "Conformation" and in the field of biology "evolution", refers to change the spatial array and molecular structure, the formation of a new structure and function. General view, transformation process refers to the process of transition from one form of movement, things changed to another form of movement. At present, "transformation," the term has been widely used in sociology and economics, urban development research according China's urban social, economic and regional. From the perspective of modern social and economic development, China's urban has entered the phase of transition. According to Lian Yuming's research, foundation for Chinese overall urbanization is weak, in transition must attention following aspects: first, "globalization" trend in the information age, This is the most distinctive features of the era; During the transition period, trends of "marketization", it is reform with Chinese characteristics, it is urban development face challenges; stage of "Reconstruction", this is the stage of current city development features. The transformation should be based on its function and the changing role to innovate and improve the management model [11].
According to different research objects, and to meet the actual needs and in conformity with the requirements of scientific development, make corresponding definition of "transformation" .This paper is based on this principle to use the concept of "transformation", on the basis of current research achievements, further defined the connotation of green transformation. Green transformation essence is traditional economy transition to a green economy, Unsustainable development transition to sustainable development. Industrial civilization transition to ecological civilization. Developping the green economy is the green of the overall goal and basic approach. Developing the green economy is the Green transformation of the overall objectives and fundamental ways. The paper argues that the" regional green transformation" is ecological carrying capacity constraints, to the construction of ecological civilization is the dominant, based on circular economy system innovation and unhook, realizing enterprise's green manufacturing. It is green government supervision; industry and the public participation, coordinated develop the regional new Complex Giant Systems. Making the regional economic system change adapts green economy from traditional economy Form. The science developing mode is in harmony with society energy-efficient and low pollution. It emphasizes the use of sustainable consumption and production mode to replace traditional resource intensive development mode .Separation of economic growth and resource consumption, environmental pollution, and ultimately achieve the goal of sustainable development.

\section{REGIONAL GREEN TRANSITION SYSTEM}

\subsection{A open complex giant system}

The open complex giant system is come from Xuesen Qian's discussions in different occasions, which point out the open complex giant system has the following characteristics:

1) The system scale is large, it's gigantism;

2)The system components remarkable differences in each other, more of breed of design and color, it's called heterogeneity;

3) The system is integrated in accordance with the way of hierarchy; it's called levels of grade;

4) Interplay in non linearity, it's called non linearity;

5) A continuous exchange of substances, energy, information between the system and environment, it's called openness.

There are much interaction and contact among system, other systems and the environment. The system should keep a continuing exchange of substances, energy, information between it and the outside, or it will become a isolating system. But the 
system is a dissipative structure, which means if we want to guarantee the sustainable development of system, we must keep the openness and exchange between it and the environment. So the system is open, it can be influence by the environment, and it bound up the environment, they interaction each other, and it will be the style which could adapt to the environment better. Qian designed all above characteristics complicacy. Or Comprehensive up the gigantism of scale, heterogeneity of components, the levels of grade to the structure, the non linearity of interaction, the openness for the environment, the dynamic of behavior, what is the characteristics of system is complexity.

Green transformation complex system studied the complex of giant system that combined by different elements in different levels. It use the method of system engineering, emphasize the relationship between the system structure and system behavior, divide the whole system to many subsystem which contact but independent each other according to the coordination characteristics and contact between its each level and elements. Evaluate the system by its oneness and levels; act the role in the causal relationship of its subsystems and the subsystem's internal clearly. Research the feedback loops that exist in the system.

\subsection{The synergy and evolution system}

From the point of the view of a modern system science, Synergy refers to a harmony state of the components within the system. It is a self-organizing process that interacts between the components and the order parameters to make the system from disorder chaos state to macro order state in the open systems conditions far from equilibrium. System self-organization process is the interaction process between the system components. A component of behavioral changes would inevitably lead to the response of other components of the corresponding changes in behavior. In turn, it affects the components to form a complex interactive network relationship. Therefore, the system self-organization process must be a dynamic process.

Innovative subjects with their innovative behavior and new advantages participate in the integration division of labor to realize the innovation elements of a comprehensive integration. Through system integration and complementary advantages to further realize the strategic cooperation, and embrace more non technological factors, showing innovation continuity, span and open. Systems integration makes the relationships, behaviors, goals and functions of innovation subject into consistent. but synergy makes these individual elements achieve the synergistic effect of $1+1>2$. The system innovation collaboration is a synergistic and competition mechanism that emphasis on innovative competition and synergistic co-exist. Innovation competition can promote system innovation creative changes. Innovation synergy expands the favorable local fluctuation of system innovation by interactive elements. Cooperative competition stems from Industrial economic dynamics and complexity. The leading force to influence main strategy behavior choice is the uncertainty result from the dynamics. From the practice of innovation development and economic growth, the innovation systematization effecting the function development, depends on institution, policy and the relevant network system linkage effect.

\section{ACKNOWLEDGEMENTS}

Shandong collaborative innovation center of energy economy (2014 SDXT011)

\section{REFERENCES}

[1] John Rensenbrink. Against All Odds: The Green Transformation of American Politics. Raymond, ME: Leopold, 1999.

[2] Peter Wallshall. A Green Transformation of Spirit?. Whole earth, spring 2002, issue 107:77.

[3] Madden, Jenifer Joy. The Green Roadmap. The Environmental Magazine, 2009, Vol. 20 Issue 2:28-29.

[4] Huang Lucheng. A discussion about regional innovation system research. Scientific management, 2000 (2):43-48.

[5] Hu Angang. China: green development and green GDP (1970-2001 year). China science fund. 2005, (02): 84-89.

[6] Huang Rongbing. Entropy and self-organization in the resource-based urban industrial transition, Journal of Harbin Institute of Technology (Social Science Edition), 2006, (05):64-68.

[7] Yu Hai. China's "five-second" green development roadmap. Environmental Protection, 2011, (01)12-13.

[8] Zhu Dajian. PS $\mathrm{R}$ methodologies of urban green transformation. Journal of Tongji University (Social Science, the), 2011 (08):37-38.

[9] Chinese Academy of Social Sciences Institute of Industrial Economics research group. The green transformation of the Chinese industry. China Industrial Economy, 2011 (04):5-6.

[10] Li Xiaoxi, Hu Biliang. The new transformation of the Chinese economy. China encyclopedia press, 2011:350353.

[11] Zhang Zilin. Review and reflection of the urbanization process in China. Chinese Economic Herald, 2010.04.30. http://www.ciudsrc.com/new_xinwen/yaowen/2010-0430/4970.html 